(c) American Dairy Science Association, 2006.

\title{
An Analysis of the Effectiveness of Heat-Killed Lactic Acid Bacteria in Alleviating Allergic Diseases
}

\author{
T. Sashihara, ${ }^{1}$ N. Sueki, and S. Ikegami \\ Department of Lactic Acid Bacteria Research, Institute of Food Functionality Research, Division of Research and Development, \\ Meiji Dairies Corporation, 540 Naruda, Odawara, 250-0862 Kanagawa, Japan
}

\begin{abstract}
Allergic diseases are reported to be caused by a skew in the balance between $\mathrm{T}$ helper type 1 and 2 cells. Because some lactic acid bacteria have been shown to stimulate IL-12 (p70) production, which in turn shifts the balance between the $\mathrm{T}$ helper type 1 and 2 cell response from the latter to the former, they have the potential to either prevent or ameliorate disease conditions or both. They have therefore been extensively studied in the recent past for their probiotic activities. Nevertheless, much less information is available concerning the microbial factors that determine the straindependent ability to affect the production of cytokines. The objectives of our study were first to select potentially probiotic lactobacilli that strongly stimulate cytokine production in vitro, and then to determine whether the selected Lactobacillus strains could suppress antigen-specific IgE production in vivo by using allergic model animals. Finally, our investigation was extended to analyze which bacterial components were responsible for the observed biological activity. Twenty strains of heat-killed lactobacilli isolated from humans were screened for their stimulatory activity for the production of IL-12 (p70) by murine splenocytes in vitro. The results showed that some strains of Lactobacillus plantarum and Lactobacillus gasseri had a higher stimulatory activity for IL-12 (p70) production than the other lactobacilli tested; however, this effect was strain dependent rather than species dependent. Oral administration of the heat-killed strains that showed higher stimulatory activity for IL-12 (p70) production tended to reduce the serum antigen-specific IgE levels in ovalbumin-sensitized BALB/c mice compared with the controls. Among the lactobacilli tested, L. gasseri OLL2809 showed the highest activity in reducing the level of antigen-specific IgE. Furthermore, the stimulatory activity for IL-12 (p70) production was found to be reduced after treating the lactobacilli with $\mathrm{N}$-acetyl-murami-
\end{abstract}

Received February 15, 2006.

Accepted March 23, 2006.

${ }^{1}$ Corresponding author: toshihiro_sashihara@meiji-milk.com dase and to be positively correlated with the amount of peptidoglycan in the cells. The present data suggest that L. gasseri OLL2809 is a good candidate for potential probiotics in terms of either the prevention or amelioration of allergic diseases or both. In addition, the strain-dependent stimulatory activity for IL-12 (p70) production was found to be due, at least in part, to the amount of peptidoglycan present in the cells.

Key words: probiotics, allergy, Lactobacillus gasseri, peptidoglycan

\section{INTRODUCTION}

The recent increase in allergic diseases such as atopic dermatitis, atopic eczema, and allergic rhinitis has been, and continues to be, a serious social problem in many countries. Such type-I allergic diseases (hypersensitivity reactions) are characterized by an elevation in serum IgE levels (Dreborg, 2002), which is generally thought to be caused by a skewed balance between $\mathrm{T}$ helper type 1 (Th1) and type 2 (Th2) cells (Shirakawa et al., 1997; Prescott et al., 1999; Hopkin, 2002). T helper type 1-derived cytokines principally influence cell-mediated immune functions such as triggering the killing of intracellular parasites by macrophages. $T$ helper type 2 cytokines are primarily implicated in the mobilization of the humoral responses dominated by $\mathrm{IgE}$ that are required for the elimination of helminth infections (Kidd, 2003). The balance between the 2 types of responses is considered to be important in maintaining homeostasis in the host because a number of diseases that have been associated with a skewed Th1 or Th2 response are linked to the abnormal production of these cytokines (Kidd, 2003).

In the case of type-I allergic reactions, IL-4 produced by Th2 cells plays a crucial role. Interleukin- 4 promotes B lymphocyte Ig isotype switching from IgG to IgE and serves to increase the circulating levels of total and allergen-specific IgE (Punnonen et al., 1994; Cross et al., 2001). Conversely, IFN- $\gamma$ produced by Th1 cells can downregulate IL-4 expression and reduce B cell Ig isotype switching (Pene et al., 1988). Therefore, in allergic patients, it could be important to shift the skewed 
balance between Th1 and Th2 cells from the Th2 side toward the Th1 side to reduce serum IgE levels.

A number of studies have reported that several strains of microorganisms, including lactic acid bacteria (LAB), display stimulatory properties on the innate immune system via cells such as macrophages and dendritic cells (Gill, 1998). Lactic acid bacteria are nonpathogenic gram-positive inhabitants of normal human microflora; some have been shown to have beneficial health effects. For instance, they induce the production of IL-12 (p70) by macrophages and dendritic cells and act synergistically with IL-18 to enhance the proliferation of Th1 cells from naïve T helper cells. This in turn stimulates IFN- $\gamma$ production to promote the Th1 phenotype, and suppresses IL-4 production to reduce the Th2 phenotype (Hessle et al., 2000; Cross et al., 2001; Cross and Gill, 2001). In addition, oral administration of these LAB has been shown to suppress the production of IgE in allergic model animals (Matsuzaki et al., 1998; Ishida et al., 2003; Fujiwara et al., 2004) and to ameliorate symptoms of allergic diseases in human clinical tests (Kalliomaki et al., 2001). Therefore, LAB have been expected to function as immunostimulatory probiotics and to be used for the production of fermented foods. However, these biological activities have been shown to be dependent on the strains rather than the species (Ishida et al., 2003; Fujiwara et al., 2004).

In contrast, many studies have focused on the components of LAB that exhibit stimulatory activity on the innate immune system (Yoshimura et al., 1999; Cross and Gill, 2001). Evidence from these studies has shown that bacterial components such as peptidoglycan (PGN) and lipoteichoic acid (LTA) present in the cell walls of gram-positive bacteria, or oligonucleotides with specific motifs are involved in the activation of innate immune systems via pattern recognition receptors called Tolllike receptors (TLR; Lien and Ingalls, 2002; Hopkins and Sriskandan, 2005). Nevertheless, much less information is available on the microbial factors that determine the ability to induce cytokines in a strain-dependent manner. Understanding the immunostimulatory activities in terms of the components of bacterial cells could provide further opportunities for utilizing such beneficial LAB as probiotics.

The objectives of the present study were to select potentially probiotic lactobacilli that could both strongly stimulate IL-12 (p70) production and suppress antigen-specific IgE production when they were orally administered to allergic model animals. In addition, we attempted to elucidate the bacterial components responsible for the beneficial biological activity.

\section{MATERIALS AND METHODS}

\section{Mice}

Five-week-old specific pathogen-free male BALB/c mice were purchased from Japan SLC (Shizuoka, Ja- pan) and were maintained on a standard diet (Oriental MF Diet; Oriental Yeast Co., Ltd., Tokyo, Japan). All experiments were performed when the mice were 6 - to 9 -wk old. The experimental protocols were approved by the Animal Care Committee of the Institute of Food Functionality Research.

\section{Bacterial Strains and Growth Conditions}

Lactobacilli were isolated from the feces of young Japanese women volunteers using lactobacilli-selective plates (Becton Dickinson, Cockeysville, MD). Twenty strains of homolactic-fermenting lactobacilli from a total of 273 isolates were selected for their gastric and bile acid resistance. Identification of the 20 strains was confirmed by $16 \mathrm{~S}$ rDNA nucleotide sequences, and patterns of carbohydrate consumption were determined by an API 50 CHL kit (BioMérieux, Marcy L'Etoile, France) and other biochemical methods (K. Kimura, C. Mizoguchi, and T. Nishio; Dept. Lactic Acid Bacteria Res., Inst. Food Functionality Res., Division of Research and Development, Meiji Dairies Corp., Kanagawa, Japan; unpublished data).

Lactobacillus plantarum JCM $1149^{\mathrm{T}}$, Lactobacillus gasseri JCM $1131^{\mathrm{T}}$, Lactobacillus crispatus $\mathrm{JCM} 1185^{\mathrm{T}}$, Lactobacillus amylovorus JCM $1126^{\mathrm{T}}$, Bifidobacterium bifidum JCM $1255^{\mathrm{T}}$, Bifidobacterium longum JCM $1217^{\mathrm{T}}$, Lactococcus lactis JCM $1248^{\mathrm{T}}$, Bacteroides vulgatus JCM 5826 ${ }^{\mathrm{T}}$, and Escherichia coli JCM $1649^{\mathrm{T}}$ were purchased from the Japan Culture Collection (Riken, Wako, Japan).

All microorganisms, with the exception of Bif. bifidum JCM $1255^{\mathrm{T}}$, Bif. longum JCM $1217^{\mathrm{T}}$, Bac. vulgatus JCM $5826^{\mathrm{T}}$, and E. coli JCM $1649^{\mathrm{T}}$, were grown in de Man, Rogosa, and Sharpe broth (Becton Dickinson) at $37^{\circ} \mathrm{C}$ for $18 \mathrm{~h}$. The others were grown anaerobically in Gifu anaerobic medium broth (Nissui, Tokyo, Japan) using AnaeroPack (Mitsubishi Gas Chemical, Tokyo, Japan) at $37^{\circ} \mathrm{C}$ for $18 \mathrm{~h}$. After fermentation, the cells were harvested in a refrigerated centrifuge $(10,000 \times$ $g, 15 \mathrm{~min}$ ) and washed twice with saline solution followed by one wash with water. The cells were resuspended in distilled water, heat killed at $75^{\circ} \mathrm{C}$ for 60 min, and lyophilized. The lyophilized cells were resuspended in PBS ( $\mathrm{pH} 7.2)$ at a concentration of $200 \mu \mathrm{g} /$ $\mathrm{mL}$ and used for in vitro assays.

\section{In Vitro Cytokine Production Assay}

BALB/c mice ( $\mathrm{n}=4$ ) were immunized i.p. with $20 \mu \mathrm{g}$ of ovalbumin (OVA; Wako Pure Chemical Industries, Osaka, Japan) and $2 \mathrm{mg}$ of $\mathrm{Al}(\mathrm{OH})_{3}$ in $0.2 \mathrm{~mL}$ of saline. After $8 \mathrm{~d}$, the mice were killed by dislocation. Their spleens were removed aseptically, teased apart with 
tissue forceps in $10 \mathrm{~mL}$ of RPMI 1640 medium (Invitrogen, Carlsbad, CA) containing $10 \%$ (vol/vol) heatinactivated fetal bovine serum (FBS; Intergen, Purchase, NY) supplemented with $100 \mathrm{U} / \mathrm{mL}$ of penicillin $\mathrm{G}, 100 \mu \mathrm{g} / \mathrm{mL}$ of streptomycin, $0.05 \mathrm{~m} M 2$-mercaptoethanol, $2 \mathrm{~m} M$ L-glutamate, $1 \mathrm{~m} M$ sodium pyruvate, and $0.1 \mathrm{~m} M$ nonessential AA (10\% FBS-RPMI 1640); and centrifuged at $450 \times g$ for $5 \mathrm{~min}$. Erythrocytes were lysed for $5 \mathrm{~min}$ at room temperature in a buffer containing $0.15 M \mathrm{NH}_{4} \mathrm{Cl}, 10 \mathrm{~m} M \mathrm{KHCO}_{3}$, and $10 \mu M$ EDTA ( $\mathrm{pH}$ 7.2). Ten milliliters of fresh medium was added and the cells were centrifuged at $450 \times g$ for 5 min and then counted. Splenocytes $\left(2.5 \times 10^{6}\right.$ cells $\left./ \mathrm{mL}\right)$ were cultured in 24-well tissue culture plates in $10 \%$ FBS-RPMI 1640 medium containing OVA at a final concentration of $100 \mu \mathrm{g} / \mathrm{mL}$ in the absence (control) or in the presence of $1 \mu \mathrm{g} / \mathrm{mL}$ of heat-killed LAB. The tissue culture supernatants were collected after $2 \mathrm{~d}$ to measure the IL-12 (p70) and after $6 \mathrm{~d}$ to measure the IFN- $\gamma$ and IL-4. In terms of the cultivation periods and the concentrations of heat-killed LAB, these experimental conditions were optimized to compare the ability of each strain to stimulate the efficient production of cytokines.

\section{In Vivo and Ex Vivo Assays}

An experimental allergy model described by Matsuzaki et al. (1998) was used in this study, with minor modifications. Briefly, 80 mice were divided into 8 groups ( $\mathrm{n}=10$ per group) on the basis of their weight. They were immunized i.p. with $0.2 \mu \mathrm{g}$ of OVA/g of body mass and $0.1 \mathrm{mg}$ of $\mathrm{Al}(\mathrm{OH})_{3} / \mathrm{g}$ of body mass in $0.2 \mathrm{~mL}$ of saline on d 0 and 14. The lyophilized, heat-killed cells, prepared as described above, were mixed in the standard diet (dry powder) at a concentration of $0.1 \%$, and mice were allowed free access to the diet throughout the experimental period (from d 0 to 21). Mice were anesthetized with diethyl ether on d 21, sera were collected, and the concentrations of OVA-specific IgE antibody were determined by ELISA.

After sacrifice by dislocation, the spleen and mesenteric lymph nodes (MLN) were removed aseptically from each mouse and were further used for ex vivo cytokine production assays. Splenocytes $\left(2.5 \times 10^{6}\right.$ cells/ $\mathrm{mL})$ and MLN cells $\left(1.25 \times 10^{6}\right.$ cells $\left./ \mathrm{mL}\right)$, prepared as described above, were cultured in 24-well and 48-well tissue culture plates, respectively, in 10\% FBS-RPMI 1640 medium containing OVA at a final concentration of $100 \mu \mathrm{g} / \mathrm{mL}$. The tissue culture supernatants were collected after $2 \mathrm{~d}$ for determination of IL-12 (p70) and after $6 \mathrm{~d}$ for IFN- $\gamma$ and IL-4, as well as the in vitro cytokine production assay.

\section{Analysis of Cytokines and Serum OVA-Specific IgE}

Interferon- $\gamma$, IL-4, and IL-12 (p70) concentrations were determined using commercially available ELISA kits (BD Biosciences, Franklin Lakes, NJ). The operating procedures provided by the manufacturer were strictly followed.

Serum OVA-specific IgE was determined by ELISA without depleting IgG, as described by Ito et al. (1997), with the modification that a biotinylated rat antimouse IgE mAb (BD Biosciences) and a streptavidin-horseradish peroxidase conjugate (BD Biosciences) were used for the detection. An OVA-specific IgE titer in a highly positive serum pool was obtained by sensitizing mice with $20 \mu \mathrm{g}$ of OVA and $2 \mathrm{mg}$ of $\mathrm{Al}(\mathrm{OH})_{3}$ twice in the same manner as described above, and the titer in the pool was defined as 10,000 arbitrary units (AU)/mL.

\section{Enzymatic Degradation of L. gasseri OLL2809}

The lyophilized L. gasseri OLL2809 was suspended in $0.1 M$ Tris- $\mathrm{Cl}(\mathrm{pH} \mathrm{7.0)}$ ) at a concentration of $4 \mathrm{mg} / \mathrm{mL}$. The cell suspension was mixed with an equal volume of $0.1 M$ Tris-Cl ( $\mathrm{pH}$ 7.0) containing different concentrations of trypsin (0 to $200 \mu \mathrm{g} / \mathrm{mL}$; Wako) or mutanolysin (0-100 $\mu \mathrm{g} / \mathrm{mL}$; Sigma, St. Louis, MO), and the mixture was incubated at $37^{\circ} \mathrm{C}$ for different periods (up to 30 $\mathrm{min}$ ). After the enzymes were inactivated by heating at $75^{\circ} \mathrm{C}$ for $60 \mathrm{~min}$, the suspensions were added to the culture of splenocytes to a final lyophilized cell concentration of $1 \mu \mathrm{g} / \mathrm{mL}$, and the stimulatory activity for IL12 (p70) production was measured in vitro as described.

\section{PGN Measurement}

The amount of PGN in the bacterial cells was determined using a silkworm larva plasma test (Wako). The principle of this method has been described elsewhere (Wako Pure Chemical Industries, 1995). Briefly, the lyophilized cells were disrupted in a $2-\mathrm{mL}$ microtube with zirconia beads $(0.1 \mathrm{~mm})$ using a MultiBead Shocker [model MB601(S); Yasui Kikai, Osaka, Japan] at $2500 \mathrm{rpm}$ at $4^{\circ} \mathrm{C}$ for $15 \mathrm{~min}$; the procedure was repeated 4 times. The samples were allowed to settle for $30 \mathrm{~s}$, and the crude cell extracts were corrected. Fifty microliters of the arbitrary diluted crude cell extracts and an equal volume of the silkworm larva plasma test solution were then mixed quickly in a 96-well microplate. The reaction time at which the absorbance at $650 \mathrm{~nm}$ reached 0.1 , because of the formation of melanin, was measured using a temperature-controlled $\left(30^{\circ} \mathrm{C}\right)$ microplate reader. A standard curve was prepared for commercially available PGN derived from Staphylococcus aureus (Wako), ranging from 0.6 to $9,400 \mathrm{ng} / \mathrm{mL}$. 


\section{LTA ELISA}

A sandwich ELISA was developed in this study for measuring LTA. A rabbit anti-LTA polyclonal antibody (Biogenesis, Poole, UK) for Staph. aureus at a concentration of $2 \mu \mathrm{g} / \mathrm{mL}$ was incubated overnight at $4^{\circ} \mathrm{C}$ in a 96-well Nunc Maxisorp Immuno-plate (Nunc A/S, Roskilde, Denmark). After 3 washes, the plate was blocked for $1 \mathrm{~h}$ with PBS containing $1 \%$ BSA to prevent nonspecific binding. One hundred-microliter aliquots of standard LTA derived from Staph. aureus (Sigma) and the arbitrary diluted crude cell extracts, prepared in the aforementioned PGN measurement, were added to the plate, and it was incubated at room temperature for $1 \mathrm{~h}$. After washing 3 times, the plate was incubated with a mouse $\mathrm{IgG}_{3}$ anti-LTA mAb (Biogenesis) for 1 $\mathrm{h}$ at $37^{\circ} \mathrm{C}$. The plate was washed 10 times and then incubated with $2 \mu \mathrm{g} / \mathrm{mL}$ of donkey antimouse IgG-peroxidase conjugate (Chemicon, Temecula, CA). A color reaction was obtained with $N, N, N^{\prime}, N^{\prime}$-tetramethylbenzidine substrate-chromogen solution (Dako, Carpinteria, CA). The reaction was stopped after $1 \mathrm{~h}$ by the addition of $1 \mathrm{~N} \mathrm{H}_{2} \mathrm{SO}_{4}$ and absorbance values were measured at $450 \mathrm{~nm}$ after subtracting the absorbance at $570 \mathrm{~nm}$. A standard curve was prepared for purified LTA derived from Staph. aureus (Sigma), ranging from 0.3 to $20 \mu \mathrm{g} / \mathrm{mL}$. The LTA ELISA did not give a crossreaction with other bacterial cell wall components such as PGN from Staph. aureus (50 $\mu \mathrm{g} / \mathrm{mL}$; Sigma) and lipopolysaccharide from $E$. coli O111:B4 $(100 \mathrm{ng} / \mathrm{mL}$; Wako).

\section{Statistical Analysis}

Data were expressed as the mean \pm standard deviation. Statistical differences between the groups were analyzed by a paired Student's $t$-test or a one-way ANOVA, followed (if justified) by the Fisher partial least squares difference test. Differences were considered significant when the $P$-value for the effect was less than 0.05 .

\section{RESULTS}

\section{Cytokine-Stimulatory Activities of Different Strains of Lactobacilli}

We first examined the ability of the 20 strains of heatkilled lactobacilli isolated from humans and their type strains to induce IL-12 (p70) and IFN- $\gamma$ and to reduce IL-4 in murine splenocytes. Table 1 shows that after 2 $\mathrm{d}$ of incubation, the production of IL-12 (p70) was not stimulated in the control. Incubation with various strains of lactobacilli induced IL-12 (p70) production up to $5,000 \pm 1,000 \mathrm{pg} / \mathrm{mL}$. Some strains, including $L$. plantarum and L. gasseri, strongly enhanced IL-12 (p70) and IFN- $\gamma$ production. Almost no stimulatory activity for IL-12 (p70) production was detected in the remaining strains.

Correlations $(P<0.05)$ were observed between the cytokines produced; for example, an increase in the concentration of IL-12 (p70) resulted in an increase in IFN- $\gamma$ and a coincidental decrease in IL- 4 production. The stimulatory activities for cytokine production by the cells were varied even within the same species. For example, L. plantarum JCM $1149^{\mathrm{T}}$ showed no activity, whereas other strains of $L$. plantarum derived from humans showed strong activities. The same phenomenon was observed in strains of $L$. crispatus, indicating that the stimulatory activity for IL-12 (p70) production is strain dependent rather than species dependent. Based on these observations, we selected the strains L. plantarum MEP170402, L. gasseri MEP170407, L. gasseri OLL2809, and L. gasseri MEP170413 as strong inducers of IL-12 ( $\mathrm{p} 70$ ) production and used them for further in vivo assays.

\section{Effect of Lactobacilli on Antigen-Specific IgE Levels in OVA-Sensitized Mice}

We investigated whether the selected heat-killed strains had the ability to reduce antigen-specific IgE levels in OVA-sensitized BALB/c mice when orally administered. In this experiment, groups administered $L$. gasseri JCM $1131^{\mathrm{T}}$ as a high IL-12 (p70) inducer and L. crispatus JCM $1185^{\mathrm{T}}$ and L. plantarum JCM $1149^{\mathrm{T}}$ as low inducers were also investigated to compare the abilities of these type strains with those of the selected strains.

During the experimental period, the mean food intake per mouse was 2 to $2.5 \mathrm{~g} / \mathrm{d}$. There was no significant difference in their weights. The result showed that $L$. crispatus $\mathrm{JCM} 1185^{\mathrm{T}}$ and $L$. plantarum $\mathrm{JCM} 1149^{\mathrm{T}}$, which had lower stimulatory activities for IL-12 (p70) production, as well as L. plantarum MEP170402 did not affect the OVA-specific IgE levels (Figure 1). Lactobacillus gasseri JCM $1131^{\mathrm{T}}$ and L. gasseri MEP170407 decreased the OVA-specific IgE levels, although the difference did not reach statistical significance $(P=0.072$ and 0.064 , respectively). Administration of $L$. gasseri OLL2809 was found to significantly reduce the OVAspecific IgE levels $(P<0.05)$. Overall, the OVA-specific IgE levels tended to be reduced in those groups administered strains that showed higher stimulatory activity for IL-12 (p70) production.

\section{Cytokine Production by Splenocytes and MLN Cells Ex Vivo}

To investigate the effects of oral administration of strains of heat-killed LAB on systemic immune re- 
Table 1. Production of cytokines (means \pm SD) by murine splenocytes from ovalbumin (OVA)-sensitized mice when stimulated by OVA in the absence (control) or presence of heat-killed microorganisms

\begin{tabular}{|c|c|c|c|}
\hline Microorganism & $\begin{array}{l}\text { IL-12 (p70), } \\
\text { pg/mL }\end{array}$ & $\begin{array}{l}\text { IFN- } \gamma \\
\mathrm{ng} / \mathrm{mL}\end{array}$ & $\begin{array}{l}\text { IL-4, } \\
\mathrm{pg} / \mathrm{mL}\end{array}$ \\
\hline Control & $0 \pm 0$ & $0.4 \pm 0.2$ & $265 \pm 75$ \\
\hline Lactobacillus plantarum JCM $1149^{\mathrm{T}}$ & $39 \pm 26$ & $10.6 \pm 3.4^{*}$ & $102 \pm 53^{*}$ \\
\hline L. plantarum MEP170401 & $4,907 \pm 1,160^{* *}$ & $30.4 \pm 7.0^{* *}$ & $34 \pm 11^{* * *}$ \\
\hline L. plantarum MEP170402 & $4,723 \pm 971^{* *}$ & $26.9 \pm 10.4^{*}$ & $35 \pm 6^{* *}$ \\
\hline L. plantarum MEP170403 & $4,602 \pm 869 * *$ & $20.5 \pm 4.5^{* *}$ & $36 \pm 11^{* *}$ \\
\hline L. plantarum MEP170404 & $4,748 \pm 950 * *$ & $25.5 \pm 9.3^{*}$ & $38 \pm 9^{*}$ \\
\hline L. plantarum MEP170405 & $4,966 \pm 965^{* *}$ & $24.4 \pm 4.0^{* *}$ & $15 \pm 11^{* *}$ \\
\hline L. plantarum MEP170406 & $3,407 \pm 602^{* *}$ & $27.8 \pm 7.3^{* *}$ & $27 \pm 9^{* *}$ \\
\hline Lactobacillus gasseri JCM $1131^{\mathrm{T}}$ & $3,721 \pm 1,338^{*}$ & $28.0 \pm 5.2^{* *}$ & $43 \pm 14^{* *}$ \\
\hline L. gasseri MEP170407 & $4,521 \pm 1,101 * *$ & $27.5 \pm 5.8^{* *}$ & $35 \pm 4^{* *}$ \\
\hline L. gasseri MEP170408 & $1,213 \pm 405^{* *}$ & $19.5 \pm 6.3^{* *}$ & $64 \pm 20^{*}$ \\
\hline L. gasseri OLL2809 & $2,990 \pm 617^{* *}$ & $19.8 \pm 6.5^{* *}$ & $61 \pm 19^{*}$ \\
\hline L. gasseri MEP170410 & $3,039 \pm 627^{* *}$ & $30.9 \pm 3.6^{* *}$ & $35 \pm 9^{* *}$ \\
\hline L. gasseri MEP170411 & $1,667 \pm 285^{* *}$ & $29.7 \pm 6.8^{* *}$ & $46 \pm 14^{* *}$ \\
\hline L. gasseri MEP170412 & $43 \pm 77$ & $7.8 \pm 1.1^{* *}$ & $140 \pm 31$ \\
\hline L. gasseri MEP170413 & $3,662 \pm 582^{* *}$ & $24.8 \pm 3.0^{* *}$ & $40 \pm 12^{*}$ \\
\hline L. gasseri MEP170414 & $557 \pm 147^{* *}$ & $18.7 \pm 5.4^{* *}$ & $49 \pm 15^{* *}$ \\
\hline Lactobacillus crispatus JCM $1185^{\mathrm{T}}$ & $41 \pm 47$ & $2.7 \pm 0.7^{* *}$ & $169 \pm 43$ \\
\hline L. crispatus MEP 170415 & $0 \pm 0$ & $0.8 \pm 0.5$ & $176 \pm 62$ \\
\hline L. crispatus MEP 170416 & $0 \pm 0$ & $1.6 \pm 0.4^{*}$ & $216 \pm 80$ \\
\hline Lactobacillus amylovorus JCM $1126^{\mathrm{T}}$ & $42 \pm 292^{*}$ & $31.0 \pm 6.8^{* *}$ & $22 \pm 6^{* *}$ \\
\hline L. amylovorus MEP170417 & $0 \pm 0$ & $5.6 \pm 1.2^{* *}$ & $259 \pm 156$ \\
\hline L. amylovorus MEP170418 & $0 \pm 0$ & $4.7 \pm 2.4^{*}$ & $196 \pm 57$ \\
\hline Lactobacillus brevis MEP170419 & $0 \pm 0$ & $2.0 \pm 1.1$ & $224 \pm 57$ \\
\hline Lactobacillus casei MEP170420 & $0 \pm 0$ & $4.0 \pm 1.7^{*}$ & $181 \pm 81$ \\
\hline Bifidobacterium bifidum JCM $1255^{\mathrm{T}}$ & $0 \pm 0$ & $0.2 \pm 0.2$ & $200 \pm 69$ \\
\hline Bifidobacterium longum JCM $1217^{\mathrm{T}}$ & $0 \pm 0$ & $1.8 \pm 0.7^{*}$ & $362 \pm 110$ \\
\hline Lactococcus lactis JCM $1248^{\mathrm{T}}$ & $1,032 \pm 234^{* *}$ & $17.1 \pm 2.4^{* *}$ & $34 \pm 16^{* *}$ \\
\hline Enterococcus faecalis IFO 3971 & $4,816 \pm 1,324^{* *}$ & $31.1 \pm 7.4^{* *}$ & $47 \pm 29^{* *}$ \\
\hline Bacteroides vulgatus JCM $5826^{\mathrm{T}}$ & $43 \pm 50$ & $1.8 \pm 0.7^{*}$ & $235 \pm 60$ \\
\hline Escherichia coli JCM $1649^{\mathrm{T}}$ & $225 \pm 120^{*}$ & $18.0 \pm 1.6^{* *}$ & $46 \pm 21^{* *}$ \\
\hline
\end{tabular}

$* P<0.05 ; * * P<0.01$.

sponses in mice, we measured the ex vivo production of cytokines such as IL-12 (p70), IFN- $\gamma$, and IL-4 produced by splenocytes and MLN cells. Because of experimental constraints, only 4 of the 8 groups of mice (control, L. crispatus JCM $1185^{\mathrm{T}}$, L. gasseri OLL2809, and L. gasseri MEP170413), selected on an arbitrary basis, were analyzed. The results showed that IL-12 (p70) production by splenocytes from the mice administered L. gasseri OLL2809 and L. gasseri MEP041713 was significantly $(P<0.05)$ greater than that of the control (Figure 2). Low levels of IL-4 were observed in both splenocytes and MLN cells from mice administered $L$. gasseri OLL2809 alone, whereas IFN- $\gamma$ levels were not affected in either type of cell. These data indicate that L. gasseri OLL2809 reduced the serum OVA-specific IgE levels because of induction of IL-12 (p70) and modification of the balance between Th1 and Th2 cells in allergy-model mice.

\section{Treatment of L. gasseri OLL2809 with Mutanolysin}

To analyze which component or components of bacterial cells were principally responsible for the stimula- tory activity for IL-12 (p70) production, we initially attempted to isolate the active component or components. However, the isolation was unsuccessful because the activity was completely abolished after physical disruption of the cells using either ultrasonication or glass beads. The cells were then treated with degrading enzymes such as trypsin and mutanolysin, which is one of the $N$-acetyl-muramidases that degrade the $\beta-1,4$ linkages between $N$-acetyl-muramic acid and $N$-acetylglucosamine in bacterial cell walls. Although the stimulatory activity for IL-12 (p70) production was not affected by trypsin (data not shown), it was reduced in response to both increased concentrations of mutanolysin (Figure 3A) and increased incubation periods (Figure $3 \mathrm{~B})$. These data suggest that the stimulatory activity for IL-12 (p70) production originated components associated with the cell wall.

\section{Relationship Between IL-12 (p70)-Stimulatory Activity and Amount of PGN}

To date, a number of studies have shown that bacterial cell wall components such as PGN and LTA exhibit 


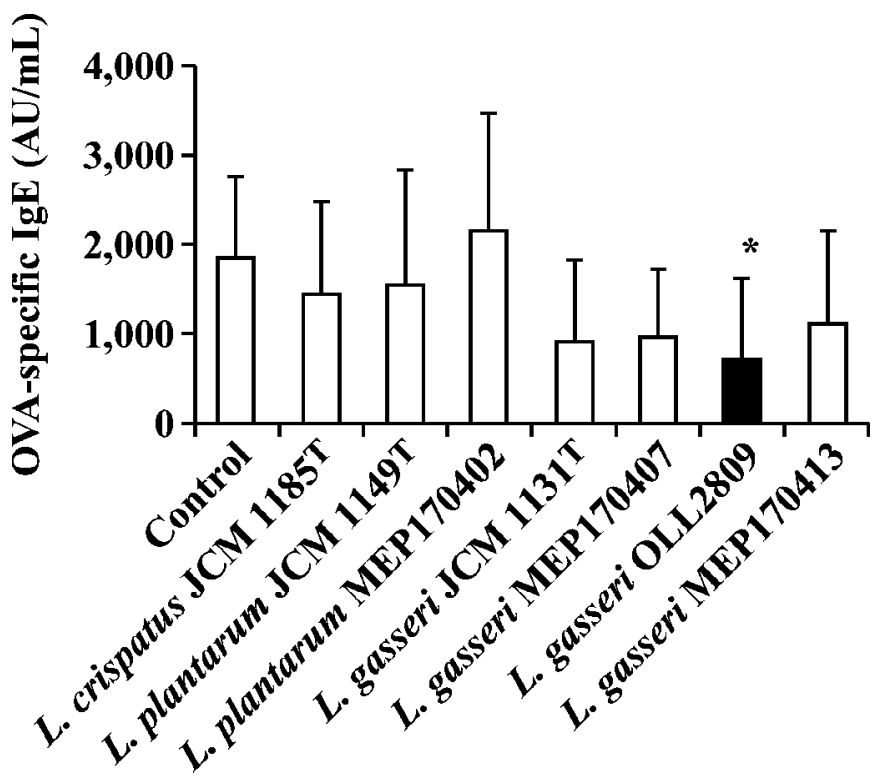

Figure 1. Effect of oral administration of heat-killed lactic acid bacteria on the serum ovalbumin (OVA)-specific IgE level in $\mathrm{BALB} / \mathrm{c}$ mice. The same experiment was repeated twice, producing similar results, and one experiment is shown. Error bars represent the standard deviations for 10 individual values. An asterisk (*) represents a significant difference from the control group $(P<0.05)$. $\mathrm{AU}=$ arbitrary units. The black bar indicates the OVA-specific IgE level in mice administered Lactobacillus gasseri OLL2809.

stimulatory activity for IL-12 (p70) production against mammalian immune cells. We therefore determined the amount of PGN and LTA in the bacterial cells tested. The results showed that the mean concentrations of PGN in the 30 strains ranged from approximately 10 to $340 \mu \mathrm{g} / \mathrm{mg}$ of dry cells, whereas LTA contained no more than $40 \mu \mathrm{g} / \mathrm{mg}$ of dry cells (Table 2). Lortal et al. (1991) reported that the amount of PGN and LTA in dry cells of Lactobacillus helveticus ATCC 12046 were 36 and $13.6 \%$, respectively; these values were estimated on the basis of the amounts of muramic acid and phosphorous. Although, the amount of LTA in the 30 strains was lower than the estimates, the amount of PGN measured in this study was not dissimilar.

The amount of PGN was relatively higher in the strains of $L$. plantarum and L. gasseri than in the other strains of lactobacilli tested. No correlation was observed between the stimulatory activities for IL-12 (p70) production and the amount of LTA (data not shown); however, there was a positive correlation with the amount of PGN $(P<0.01$, Figure 4$)$. These data suggest that the strain-dependent stimulatory activity for IL-12 (p70) production was mediated, at least in part, by the amount of PGN present in bacterial cells.

\section{DISCUSSION}

In this study, we evaluated 20 strains of potentially probiotic lactobacilli, isolated from humans, for their stimulatory activity to produce cytokines by murine splenocytes in vitro and their ability to reduce the antigen-specific IgE levels in vivo. Here, we performed experiments with heat-killed, rather than live, cells because using live cells might cause a bias in evaluating these abilities of LAB. It has been shown that not only live but also heat-killed LAB exhibit immunostimulatory activity (Matsuzaki et al., 1998; Maassen et al., 2000; Fujiwara et al., 2004). Lyophilized live cells (or even the nonlyophilized cells) of each strain contain different populations of dead cells (Nighswonger et al., 1996; Corcoran et al., 2004). This population of dead cells could be even larger than that of live cells, and this situation could occur during the preparation procedures, depending on the viability of the strains (Bucio, et al., 2005). This must affect the evaluation of the stimulatory ability when the dosage is controlled by the number of live cells. Therefore, dead cells were used to ensure that the total cell amount in all the strains was the same; this would allow evaluation of their abilities under the same conditions. The results from the study showed that some strains of $L$. plantarum and $L$. gasseri had greater IL-12 (p70) stimulatory activity than the other lactobacilli tested. In addition, the bacterial cells that showed higher IL-12 (p70) stimulatory activity also exhibited a more marked modification of the balance between Th1 and Th2 cells. With the exception of $L$. plantarum MEP170402, oral administration of the selected strains with higher IL-12 (p70) stimulatory activity generally tended to reduce the serum OVA-specific IgE levels in OVA-sensitized BALB/c mice compared with the control. Ex vivo production of IL-12 (p70) by splenocytes was induced, whereas production of IL-4 by both splenocytes and MLN cells from mice administered L. gasseri OLL2809 was suppressed compared with the control group. The reason that production of IFN- $\gamma$ was not affected ex vivo is unknown, but it could be due to the difference between in vitro and ex vivo (in vivo) reactions. This result indicates that the suppression of the OVA-specific IgE level by L. gasseri OLL2809 could be mediated by modification of the balance between Th1 and Th 2 cells by suppressing Th2 cells. Since the suppressive effect of the elevated IL-4 by LAB in murine splenocytes in vitro is abolished by adding anti-IL-12 (p70) mAb to the culture media, it is evident that IL-12 (p70) plays a crucial role in modifying the balance between Th1 and Th2 cells (Shida et al., 1998). Taken together, these results suggest that $L$. gasseri OLL2809 with higher IL-12 (p70) stimulatory 

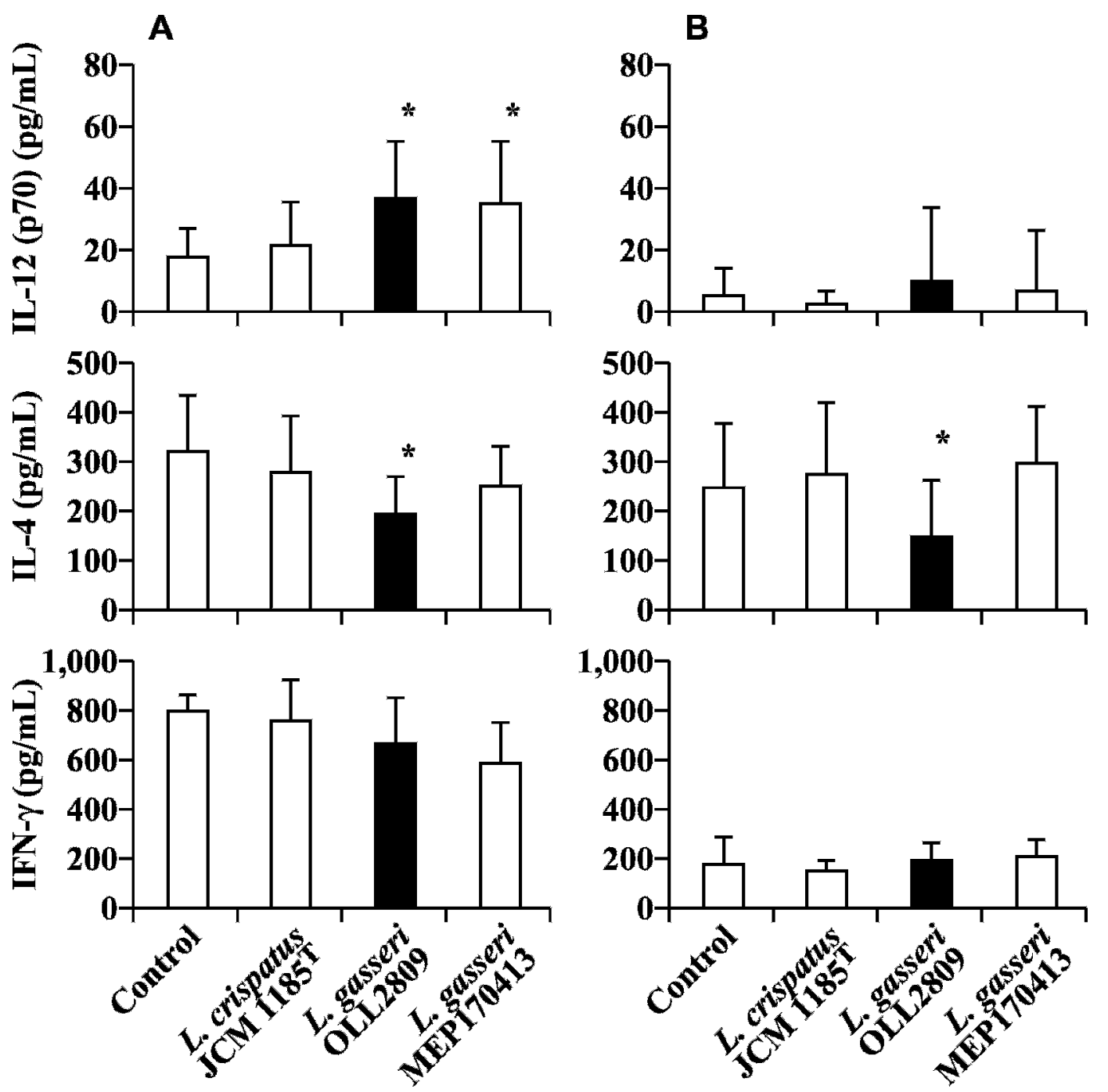

Figure 2. Cytokine production by splenocytes (A) and mesenteric lymph node cells (B) ex vivo from mice orally administered heat-killed lactic acid bacteria. The same experiment was repeated twice, producing similar results, and a typical result is shown. Error bars represent the standard deviations for 10 individual values. Asterisks $(*)$ represent a significant difference from the control group $(P<0.05)$. The black bars represent cytokine levels from mice administered Lactobacillus gasseri OLL2809.

activity in vitro has the ability to reduce antigen-specific IgE in vivo.

Several earlier studies have reported in vitro cytokine response patterns of the innate immune defense system activated by probiotic lactobacilli (Shida et al., 1998; Fujiwara et al., 2004). The activation of macrophages and dendritic cells by microorganisms is mediated by pattern recognition systems, including TLR. Among the 11 mammalian TLR discovered so far, TLR2 responds to a number of bacterial products, including components of gram-positive bacterial cell walls such as PGN and LTA (Brightbill et al., 1999; Hertz et al., 2001). The TLR2mediated signals are transferred to chromosomes and then trigger the transcription of nuclear factor- $\kappa \mathrm{B}$
mRNA to induce inflammatory cytokines (Lien and Ingalls, 2002).

Nevertheless, there is little information on why the intensity of the immunostimulatory activity differs among the bacterial strains. We therefore investigated which component in L. gasseri OLL2809 was responsible for the biological reactivity observed in murine splenocytes. However, isolation of the active component was unsuccessful, as described. Several investigations have examined the effects of gram-positive bacterial fractions on immunostimulatory activity. Michelsen et al. (2001) reported that purified PGN from Staph. aureus induced the production of IL-12 (p70) via TLR in murine bone marrow dendritic cells. Heumann et al. 

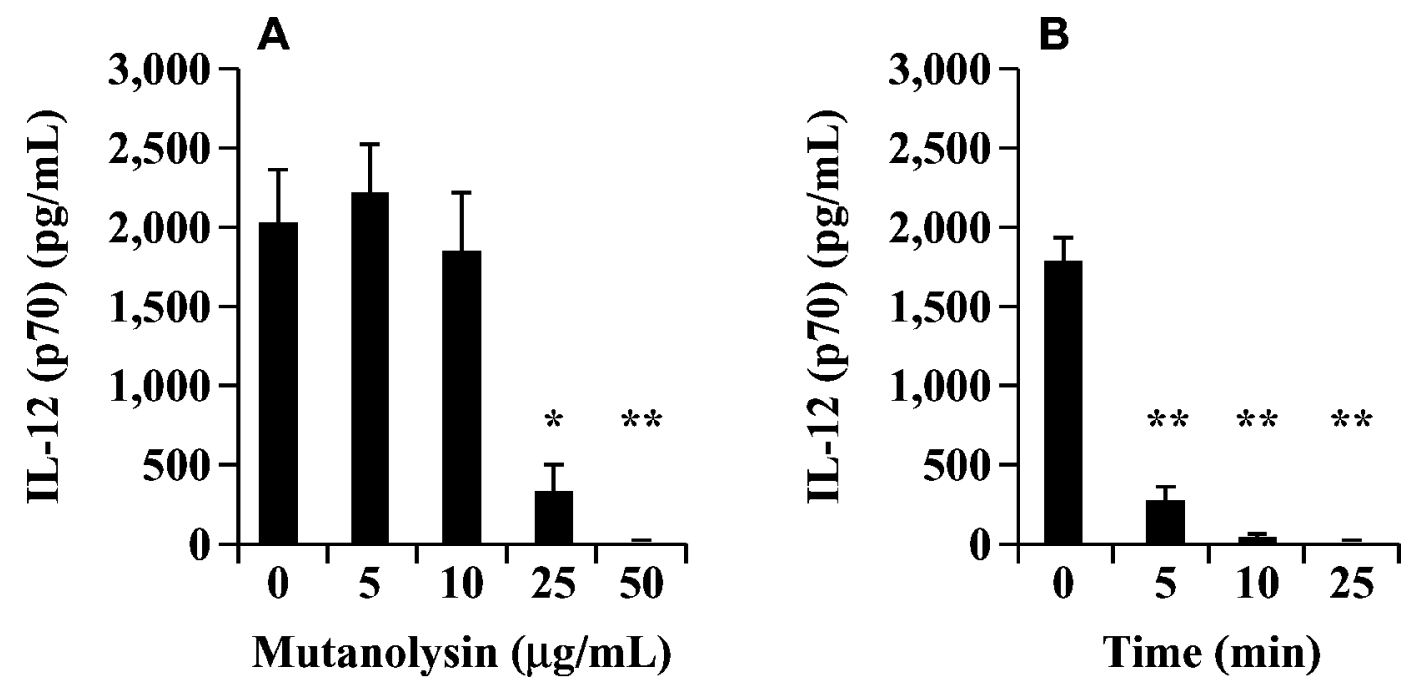

Figure 3. Decrease of IL-12 (p70) stimulatory activity of Lactobacillus gasseri OLL2809 treated with mutanolysin ( $N$-acetyl-muramidase). Lactobacillus gasseri OLL2809 was treated with different concentrations of mutanolysin at $37^{\circ} \mathrm{C}$ for $30 \mathrm{~min}(\mathrm{~A})$ and with $50 \mu \mathrm{g} / \mathrm{mL}$ of mutanolysin at $37^{\circ} \mathrm{C}$ for different incubation periods (B). Error bars represent the standard deviations for 3 individual values. $* P<0.05$; $* * P<0.01$

(1994) showed that both purified cell walls and PGN prepared from several different gram-positive bacterial species induced the production of tumor necrosis factor$\alpha$, which is one of the proinflammatory cytokines whose expression is regulated by nuclear factor- $\kappa \mathrm{B}$ as well as IL-12 (p70) in human monocytes. Nevertheless, the addition of up to $100 \mu \mathrm{g} / \mathrm{mL}$ of commercially prepared PGN (from Staph. aureus and Enterococcus faecalis) and LTA (from Staph. aureus; Sigma) did not induce IL-12 (p70) production in our in vitro experiment (data not shown). We have observed that when stimulation was carried out using $100 \mu \mathrm{g} / \mathrm{mL}$ of the tested strain, as well as the in vitro cytokine production assay using murine splenocytes, the pattern of production of tumor necrosis factor- $\alpha$ by human monocytes extracted from cord blood correlated significantly $(P<0.05)$ with that of IL-12 (p70) production by murine splenocytes, as shown in this study [S. Ikegami, M. Yamaguchi (Functional Evaluation Dept., Inst. Food Functionality Res., Division of Research and Development, Meiji Dairies Corp., Kanagawa, Japan), S. Suzuki, N. Shimojo, and Y. Kohno (Dept. Pediatrics, Chiba Univ., Chiba, Japan); unpublished data]. It is therefore assumed that the principal active component for this activation is the same in both murine splenocytes and human monocytes. In our experiment, a possible explanation for the observation that purified PGN and degraded bacterial cells were not reactive is that maintaining the intact conformation of the PGN could be a necessary prerequisite for the activation of murine splenocytes. There could also be differences among murine splenocytes, murine bone marrow dendritic cells, and human mono- cytes in terms of their reactivity toward purified PGN; this might be attributable to differences in the recognition or incorporation of PGN into the different target cells.

Experiments on the enzymatic degradation of $L$. gasseri OLL2809 and the quantification of the amount of PGN in the cells suggested that IL-12 (p70) production was, at least in part, due to the amount of PGN molecules present in the cell. Bacterial PGN comprises a polymer of the disaccharide $N$-acetyl-glucosamine$\beta(1 \rightarrow 4)-N$-acetyl-muramic acid (glycan chain) crosslinked by peptides (Delcour et al., 1999). Although a variety of chemotypes of PGN in the lactobacilli species

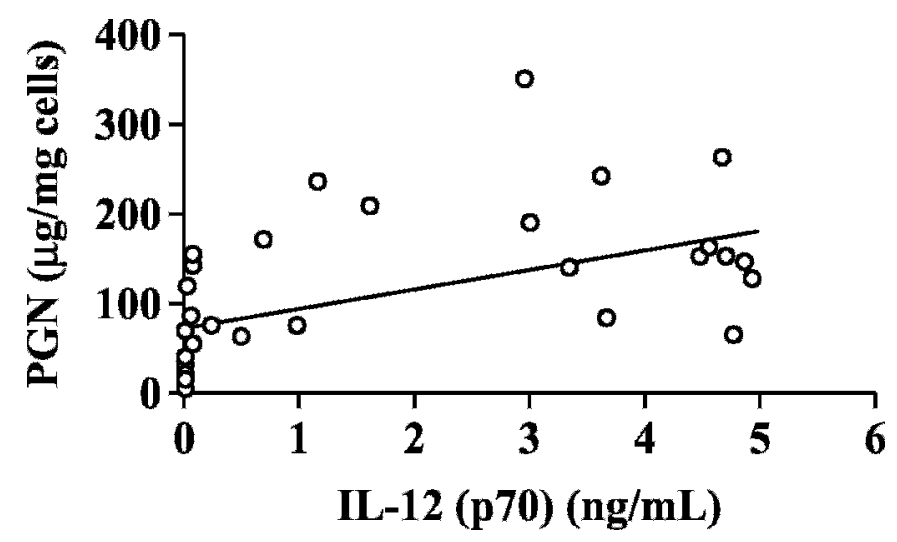

Figure 4. Relationship between IL-12 (p70)-stimulatory activity and the amount of peptidoglycan (PGN) in the cells. Interleukin-12 (p70)-stimulatory activity and the amount of PGN in the cells were positively correlated $(y=0.021 x+73.44 ; \mathrm{r}=0.5202 ; \mathrm{n}=31, P<0.01)$. 
Table 2. Amounts of peptidoglycan (PGN) and lipoteichoic acid (LTA) in the tested microorganisms ${ }^{1}$

\begin{tabular}{|c|c|c|}
\hline Microorganism & $\begin{array}{l}\text { PGN, } \\
\mu \mathrm{g} / \mathrm{mg} \text { cells }\end{array}$ & $\begin{array}{l}\text { LTA, } \\
\mu \mathrm{g} / \mathrm{mg} \text { cells }\end{array}$ \\
\hline Control & $0 \pm 0$ & $0.0 \pm 0.0$ \\
\hline Lactobacillus plantarum JCM $1149^{\mathrm{T}}$ & $46 \pm 21$ & $35.1 \pm 10.1$ \\
\hline L. plantarum MEP170401 & $140 \pm 80$ & $6.8 \pm 2.1$ \\
\hline L. plantarum MEP170402 & $254 \pm 127$ & $2.8 \pm 1.8$ \\
\hline L. plantarum MEP170403 & $155 \pm 105$ & $0.8 \pm 2.1$ \\
\hline L. plantarum MEP170404 & $147 \pm 90$ & $2.1 \pm 2.9$ \\
\hline L. plantarum MEP170405 & $120 \pm 77$ & $2.2 \pm 2.8$ \\
\hline L. plantarum MEP170406 & $133 \pm 81$ & $1.0 \pm 2.8$ \\
\hline Lactobacillus gasseri JCM $1131^{\mathrm{T}}$ & $75 \pm 58$ & $25.0 \pm 1.5$ \\
\hline L. gasseri MEP170407 & $142 \pm 91$ & $23.1 \pm 8.5$ \\
\hline L. gasseri MEP170408 & $226 \pm 232$ & $11.4 \pm 3.4$ \\
\hline L. gasseri OLL2809 & $341 \pm 336$ & $16.0 \pm 4.8$ \\
\hline L. gasseri MEP170410 & $184 \pm 106$ & $21.8 \pm 6.4$ \\
\hline L. gasseri MEP170411 & $200 \pm 143$ & $8.9 \pm 1.8$ \\
\hline L. gasseri MEP170412 & $137 \pm 100$ & $2.2 \pm 2.5$ \\
\hline L. gasseri MEP170413 & $233 \pm 157$ & $9.8 \pm 4.3$ \\
\hline L. gasseri MEP170414 & $54 \pm 51$ & $11.5 \pm 2.7$ \\
\hline Lactobacillus crispatus JCM $1185^{\mathrm{T}}$ & $145 \pm 72$ & $23.5 \pm 11.0$ \\
\hline L. crispatus MEP 170415 & $63 \pm 62$ & $1.2 \pm 1.7$ \\
\hline L. crispatus MEP 170416 & $32 \pm 26$ & $3.3 \pm 2.9$ \\
\hline Lactobacillus amylovorus JCM $1126^{\mathrm{T}}$ & $164 \pm 43$ & $16.5 \pm 14.2$ \\
\hline L. amylovorus MEP170417 & $26 \pm 16$ & $1.3 \pm 1.8$ \\
\hline L. amylovorus MEP170418 & $32 \pm 30$ & $5.8 \pm 4.8$ \\
\hline Lactobacillus brevis MEP170419 & $14 \pm 7$ & $9.9 \pm 3.2$ \\
\hline Lactobacillus casei MEP170420 & $13 \pm 11$ & $37.4 \pm 23.7$ \\
\hline Bifidobacterium bifidum JCM $1255^{\mathrm{T}}$ & $113 \pm 66$ & $0.0 \pm 1.9$ \\
\hline Bifidobacterium longum JCM $1217^{\mathrm{T}}$ & $7 \pm 3$ & $0.0 \pm 0.2$ \\
\hline Lactococcus lactis JCM $1248^{\mathrm{T}}$ & $68 \pm 30$ & $26.7 \pm 15.7$ \\
\hline Enterococcus faecalis IFO 3971 & $56 \pm 11$ & $0.0 \pm 0.8$ \\
\hline Bacteroides vulgatus JCM $5826^{\mathrm{T}}$ & $80 \pm 40$ & $0.0 \pm 0.5$ \\
\hline Escherichia coli JCM $1649^{\mathrm{T}}$ & $69 \pm 34$ & $0.0 \pm 0.5$ \\
\hline
\end{tabular}

${ }^{1}$ The measurement of each component was performed 3 times, and data are expressed as means \pm standard deviations.

are used for the systematic identification of the species, only L. plantarum exhibits differences in its AA composition when compared with the other lactobacilli tested in this study. For example, L-lysine in the third position of the peptide is substituted by meso-diaminopimelic acid in L. plantarum (Sneath, 1986). The findings of this study are particularly interesting because although recent research has highlighted the fact that gram-positive bacterial cell wall components can exhibit immunostimulatory properties, there has been no discussion regarding the differential immunostimulatory activities of different microorganisms. This is the first report showing that the observed strain-dependent stimulatory activity for IL-12 (p70) production arises, at least in part, from the amount of PGN present in gram-positive bacteria. However, we cannot exclude the possibility that secondary structures such as the degree of amidation of the free carboxyl groups or the degree of cross-linking may also affect the intensity of the immunostimulatory activity. We intend to conduct more detailed studies to investigate the relationship between PGN and the stimulatory activity for IL-12 (p70) production.

\section{ACKNOWLEDGMENTS}

We thank Katsunori Kimura and Tomoko Nishio for providing the LAB isolated from humans, and Ken-ichi Hojo, Chinami Mizoguchi, and Seiko Narushima for preparing the LAB used in this study.

\section{REFERENCES}

Brightbill, H. D., D. H. Libraty, S. R. Krutzik, R. B. Yang, J. T. Belisle, J. R. Bleharski, M. Maitland, M. V. Norgard, S. E. Plevy, S. T. Smale, P. J. Brennan, B. R. Bloom, P. J. Godowski, and R. L. Modlin. 1999. Host defense mechanisms triggered by microbial lipoproteins through Toll-like receptors. Science 285:732-736.

Bucio, A., R. Hartemink, J. W. Schrama, J. Verreth, and F. M. Rombouts. 2005. Survival of Lactobacillus plantarum 44a after spraying and drying in feed and during exposure to gastrointestinal tract fluids in vitro. J. Gen. Appl. Microbiol. 51:221-227.

Corcoran, B. M., R. P. Ross, G. F. Fitzgerald, and C. Stanton. 2004. Comparative survival of probiotic lactobacilli spray-dried in the presence of probiotic substances. J. Appl. Microbiol. 96:10241039 .

Cross, M. L., and H. S. Gill. 2001. Can immunoregulatory lactic acid bacteria be used as dietary supplements to limit allergies? Int. Arch. Allergy Immunol. 125:112-119.

Cross, M. L., L. M. Stevenson, and H. S. Gill. 2001. Anti-allergy properties of fermented foods: An important immunoregulatory mechanism of lactic acid bacteria? Int. Immunopharmacol. 1:891-901. 
Delcour, J., T. Ferain, M. Deghorain, E. Palumbo, and P. Hols. 1999. The biosynthesis and functionality of the cell wall of lactic acid bacteria. Artonie Van Leeuwenhoek 76:159-184.

Dreborg, S. 2002. The implications of nomenclature. Ann. Allergy Asthma Immunol. 89:83-85.

Fujiwara, D., S. Inoue, H. Wakabayashi, and T. Fujii. 2004. The antiallergic effects of lactic acid bacteria are strain dependent and mediated by effects of both Th1/Th2 cytokine expression and balance. Int. Arch. Allergy Immunol. 135:205-215.

Gill, H. S. 1998. Stimulation of the immune system by lactic cultures. Int. Dairy J. 8:535-544.

Hertz, C. J., S. M. Kiertscher, P. J. Godowski, D. A. Bouis, M. V. Norgard, M. D. Roth, and R. L. Modlin. 2001. Microbial lipopeptides stimulate dendritic cell maturation via Toll-like receptor 2. J. Immunol. 166:2444-2450.

Hessle, C., B. Andersson, and A. Wold. 2000. Gram-positive bacteria are potent inducers of monocytic interleukin-12 (IL-12) while gram-negative bacteria preferentially stimulate IL-10 production. Infect. Immun. 68:3581-3586.

Heumann, D., C. Barras, A. Severin, M. P. Glauser, and A. Tomasz. 1994. Gram-positive cell walls stimulate synthesis of tumor necrosis factor $\alpha$ and interleukin- 6 by human monocytes. Infect. Immun. 62:2715-2721.

Hopkin, J. M. 2002. The rise of atopy and links to infection. Allergy 57:5-9.

Hopkins, P. A., and S. Sriskandan. 2005. Mammalian Toll-like receptors: To immunity and beyond. Clin. Exp. Immunol. 140:395-407.

Ishida, Y., I. Bandou, H. Kanzato, and N. Yamamoto. 2003. Decrease in ovalbumin specific IgE of mice serum after oral uptake of lactic acid bacteria. Biosci. Biotechnol. Biochem. 67:951-957.

Ito, K., K. Inagaki-Ohara, S. Murosaki, H. Nishimura, T. Shimokata, S. Torii, T. Matsuda, and Y. Yoshikai. 1997. Murine model of IgE production with a predominant Th2-response by feeding protein antigen without adjuvants. Eur. J. Immunol. 27:3427-3437.

Kalliomaki, M., S. Salminen, H. Arvilommi, P. Kero, P. Koskinen, and E. Isolauri. 2001. Probiotics in primary prevention of atopic disease: A randomised placebo-controlled trial. Lancet 357:1076-1079.

Kidd, P. 2003. Th1/Th2 balance: The hypothesis, its limitations, and implications for health and disease. Altern. Med. Rev. 8:223-246.

Lien, E., and R. R. Ingalls. 2002. Toll-like receptors. Crit. Care Med. 30:S1-S11.

Lortal, S., M. Rousseau, P. Boyaval, and J. V. A. N. Heijenoort. 1991. Cell wall and autolytic system of Lactobacillus helveticus ATCC 12046. J. Gen. Microbiol. 137:549-559.
Maassen, C. B. M., C. van Holten-Neelen, F. Balk, M. H. den BakGlashouwer, R. J. Leer, J. D. Laman, W. J. A. Boersma, and E. Claassen. 2000. Strain-dependent induction of cytokine profiles in the gut by orally administered Lactobacillus strains. Vaccine 18:2613-2623.

Matsuzaki, T., R. Yamazaki, S. Hashimoto, and T. Yokokura. 1998. The effect of oral feeding of Lactobacillus casei strain Shirota on immunoglobulin E production in mice. J. Dairy Sci. 81:48-53.

Michelsen, K. S., A. Aicher, M. Mohaupt, T. Hartung, S. Dimmeler, C. J. Kirschning, and R. R. Schumann. 2001. The role of Tolllike receptors (TLRs) in bacteria-induced maturation of murine dendritic cells (DCs). J. Biol. Chem. 276:25680-25686.

Nighswonger, B. D., M. M. Brashears, and S. E. Gilliland. 1996 Viability of Lactobacillus acidophilus and Lactobacillus casei in fermented milk products during refrigerated storage. J. Dairy Sci. 79:212-219.

Pene, J., F. Rousset, F. Briere, I. Chretien, J.-Y. Bonnefoy, and H. Spits. 1988. IgE production by normal human lymphocytes is induced by interleukin 4 and suppressed by interferons $\gamma$ and $\alpha$ and prostaglandin $\mathrm{E}_{2}$. Proc. Natl. Acad. Sci. USA 85:6880-6885.

Prescott, S. L., C. Macaubas, T. Smallacombe, B. J. Holt, P. D. Sly, and P. G. Holt. 1999. Development of allergen-specific T-cell memory in atopic and normal children. Lancet 353:196-200.

Punnonen, J., G. Aversa, B. G. Cocks, and J. E. de Vries. 1994. Role of interleukin- 4 and interleukin-13 in synthesis of $\operatorname{IgE}$ and expression of CD23 by human B cells. Allergy 49:576-586.

Shida, K., K. Makino, A. Morishita, K. Takamizawa, S. Hachimura, A. Ametani, T. Sato, Y. Kumagai, S. Habu, and S. Kaminogawa. 1998. Lactobacillus casei inhibits antigen-induced IgE secretion through regulation of cytokine production in murine splenocytes cultures. Int. Arch. Allergy Immunol. 115:278-287.

Shirakawa, T., T. Enomoto, S. Shimizu, and J. M. Hopkin. 1997. The inverse association between tuberculin responses and atopic disorder. Science 275:77-79.

Sneath, P. H. A. 1986. Bergey's Manual of Systematic Bacteriology. Vol. 2. Williams and Wilkins, Baltimore, MD.

Wako Pure Chemical Industries. 1995. SLP Reagent Set. Bioproducts Technical Bulletin. Wako Pure Chemical Industries, Osaka, Japan.

Yoshimura, A., E. Lien, R. R. Ingalls, E. Tuomanen, R. Dziarski, and D. Golenbock. 1999. Cutting edge: Recognition of gram-positive bacterial cell wall components by the innate immune system occurs via Toll-like receptor 2. J. Immunol. 163:1-5. 